\title{
Studies on NaI/DMSO induced retro-Michael addition (RMA) reactions on some 1,5-dicarbonyl compounds
}

\author{
H SURYA PRAKASH RAO* and S JOTHILINGAM \\ Department of Chemistry, Pondicherry University, Pondicherry 605 014, India \\ e-mail: hspr@yahoo.com
}

MS received 5 August 2004; revised 29 December 2004

\begin{abstract}
Studies on the reaction of some 1,5-ketodiesters/1,5-diketones with $\mathrm{NaX}(\mathrm{X}=\mathrm{Cl} / \mathrm{Br} / \mathrm{I})$ / DMSO have shown that under microwave/thermal conditions, facile retro-Michael addition (RMA) reaction takes place instead of formation of the expected Krapcho products. Mechanistic studies have shown that the NaI/DMSO system is a better system than $\mathrm{NaCl} / \mathrm{DMSO}$ or $\mathrm{NaBr} / \mathrm{DMSO}$ to promote the RMA pathway and DMSO is an essential requirement. The electrophilic halide ion could be involved in this fragmentation reaction.
\end{abstract}

Keywords. retro-Michael addition; microwave-mediated organic reactions; retro reactions.

\section{Introduction}

Generally two alternative methods are employed for selective mono-dealkoxycarbonylation of gem-diesters to the corresponding monoesters. The first one is a straightforward, three-step procedure involving sequentially, (i) base mediated hydrolysis of the diester to the corresponding diacid, (ii) pyrolysis under reduced pressure to affect mono-decaroxylation, (iii) esterification of the resulting mono-acid to the mono-ester. ${ }^{1}$ In the alternative one-pot Krapcho procedure, the diester is heated to reflux in DMSO in the presence of sodium chloride to furnish the monoester directly. ${ }^{2}$ A few other salts such as potassium cyanide, ${ }^{3}$ sodium cyanide, ${ }^{4}$ lithium chloride ${ }^{5}$ are also found to promote this widely used reaction. We reasoned that as DMSO responds to passing microwaves due to its high dielectric constant $(46 \cdot 45),{ }^{6}$ The Krapcho method could work well under microwave irradiation. Previously Loupy et $a l^{7}$ showed that the mono-decarboethoxylation of selected diesters can be performed readily in the presence of lithium bromide and a phase transfer catalyst. However, there are no studies on microwave-mediated dealkoxycarbonylation of diesters with an inbuilt 1,5-dicarbonyl function. Therefore, in this study we have attempted decarboethoxylation of the diester $\mathbf{1 a}$ using $\mathrm{NaCl} /$ DMSO under microwave irradiation expecting the

\footnotetext{
*For correspondence
}

formation of the monoester 4 . However, surprisingly, the major products formed in the reaction are the retro-Michael addition (RMA) product, 1,3-diphenyl2-propene-2-one (chalcone, 84\%) 2a and diethyl melonate 3 ( $84 \%$; scheme 1). The expected Krapcho product, the monoester $\mathbf{4}$, was the minor product (16\%).

The RMA reaction is known to occur readily under biological conditions. ${ }^{8}$ However, only a few RMA reactions have taken place in laboratory syntheses. ${ }^{9}$ Moreover, studies on the scope of RMA reactions, particularly those involving 1,5-ketodiesters and 1,5-diketones compounds are rare, though the reaction is known to take place for some aromatic 1,5diketones during mass spectral fragmentation. ${ }^{10}$ Albrecht and coworkers ${ }^{11}$ studied the RMA reaction of selected 1,5-diketones and showed that the reaction could be improved by using steam distillation in the presence of sodium hydroxide adsorbed on glass wool as catalyst. $\mathrm{Li}$ and $\mathrm{Wang}^{12}$ studied steam-mediated RMA reaction for some 1,5-diketones present in steroid-like molecules. ${ }^{12}$

\section{Results and discussion}

Since we found an unexpected and facile RMA reaction taking place on 1a under Krapcho conditions, we set out to study the scope of the reaction. Towards this goal, we have varied reaction conditions such as the salt and the solvent used by taking the transformation of $1 \mathbf{a}$ to $\mathbf{2 a}$ as a test case. The results from 
<smiles>CCOC(=O)C(C(=O)OCC)C(CC(=O)c1ccccc1)c1ccccc1</smiles>

1a<smiles>O=C(/C=C/c1ccccc1)c1ccccc1</smiles>

2a<smiles>[CH+][PH2+]C(=O)CC(CC(=O)OCC)CC(CC(=O)OCC)c1ccccc1</smiles>

3
4

Scheme 1. Reagents and conditions: (i) NaCl, DMSO, MW, $400 \mathrm{~W}, 2$ min, quantitative, 2a, 3 : 4 = $84: 16$; (ii) $\mathrm{NaCl}$, DMSO, $160^{\circ} \mathrm{C}, 5$ h, $90 \%, \mathbf{2 a}, 3: \mathbf{4}=81: 19$.

Table 1. Reaction of diesters 1a under microwave irradiation with different conditions.

\begin{tabular}{|c|c|c|c|c|c|}
\hline Sl. no. & Reagent & Solvent & Power (W) & Time (min) & Yield of $\mathbf{2 a}(\%)$ \\
\hline 1 & $\mathrm{NaCl}$ & DMSO & 400 & 2 & 84 \\
\hline 2 & $\mathrm{NaCl}$ & DMF & 640 & 5 & No reaction \\
\hline 3 & $\mathrm{NaCl}$ & NMP & 640 & 5 & No reaction \\
\hline 4 & $\mathrm{NaCl}$ & Water & 640 & 5 & No reaction \\
\hline 5 & $\mathrm{NaCl}$ & PEG-200 & 640 & 5 & No reaction \\
\hline 6 & $\mathrm{Na}_{2} \mathrm{SO}_{4}$ & DMSO & 640 & 5 & No reaction \\
\hline 7 & K10 Clay & - & 640 & 5 & No reaction \\
\hline 8 & K10 Clay & DMSO & 640 & 5 & No reaction \\
\hline 9 & $\mathrm{~K} 10+\mathrm{NaCl}^{[\mathrm{a}]}$ & - & 640 & 5 & No reaction \\
\hline 10 & $\mathrm{Al}_{2} \mathrm{O}_{3}+\mathrm{NaCl}^{[\mathrm{a}]}$ & - & 640 & 5 & No reaction \\
\hline 11 & $\mathrm{KBr}$ & DMSO & 400 & 2 & 94 \\
\hline 12 & $\mathrm{NaBr}$ & DMSO & 400 & 2 & 87 \\
\hline 13 & $\mathrm{NaI}$ & DMSO & 400 & 2 & 97 \\
\hline 14 & $\mathrm{I}_{2}$ & DMSO & 400 & 2 & 20 \\
\hline
\end{tabular}

${ }^{[\mathrm{a}]} \mathrm{NaCl}$ coated on $\mathrm{K} 10 / \mathrm{Al}_{2} \mathrm{O}_{3}(1: 1)$

this study are gathered in table 1 . Initially we changed the solvent used in the reaction to evaluate its role and efficacy. The RMA reaction on 1a was conducted in polar solvents such as DMF (entry 2, table 1), NMP (entry 3, table 1), water (entry 4, table 1) and PEG-200 (entry 5, table 1) apart from DMSO (entry 1, table 1). In all the cases, other than where DMSO was used as a solvent there was no RMA product and the starting diester 1a was isolated as such. This result indicated that DMSO is essential for the RMA reaction. Next, we changed the salt $(\mathrm{NaCl})$ to evaluate its role in the transformation. There was no RMA product formation when $\mathrm{Na}_{2} \mathrm{SO}_{4} / \mathrm{DMSO}$ was used instead of $\mathrm{NaCl} / \mathrm{DMSO}$ (entry 6 , table 1 ). This result indicates that a halide ion is also a requirement for the RMA reaction. The RMA reaction did not take place when it was conducted under solid-phase conditions using acidic clay, Montmorillonite K10 (entry 7, table 1), Montmorillonite K10 and DMSO (1:1 by weight; entry 8 , table 1 ), Montmorillonite $\mathrm{K} 10$ and $\mathrm{NaCl}(1: 1$ by weight; entry 9 , table 1$)$ or $\mathrm{Al}_{2} \mathrm{O}_{3}$ (neutral, 100-200 mesh) and $\mathrm{NaCl}(1: 1$ by weight; entry 10 , table 1 ), supporting the fact that the reaction takes place only when both $\mathrm{NaCl}$ and DMSO are present. In all the cases microwave instrument power was raised from $400 \mathrm{~W}$ to $640 \mathrm{~W}$ and the reactants were exposed to microwaves for a period of at least $5 \mathrm{~min}$ to evaluate formation of a product.

To investigate the role of the counter halide ion on the RMA reaction, the ketodiester 1a was subjected to microwave irradiation in the presence of $\mathrm{KBr} / \mathrm{DMSO}$ (entry 11, table 1), sodium bromide in DMSO (entry 12, table 1) or sodium iodide in DMSO (entry 13 , table 1 ). It is clear from table 1 that the maximum yield of the RMA product $2 \mathbf{a}$ could be obtained when the reaction was conducted with $\mathrm{NaI} /$ DMSO. From this experiment we concluded that sodium iodide in DMSO is the best to promote the microwave-mediated RMA reaction. Moreover, unlike the $\mathrm{NaCl} / \mathrm{DMSO}$ system (scheme 1), reaction with $\mathrm{NaI} / \mathrm{DMSO}$ did not exhibit the formation of Krapcho product even in traces.

To evaluate whether the NaI/DMSO-mediated RMA reaction of 1a takes place only under microwave irradiation or takes place under thermal conditions also, we conducted the reaction under normal thermal conditions in a pre-heated oil-bath. The transformation of 1a to 2a took place smoothly at 
$160^{\circ} \mathrm{C}$ but the reaction required $5 \mathrm{~h}$ for completion and the yield of $\mathbf{2 a}$ was $96 \%$. The transformation of 1a to 2 a under thermal conditions $\left(160^{\circ} \mathrm{C}\right)$ took place even when $\mathrm{NaCl} / \mathrm{DMSO}$ was employed but the yield of enone 2a was marginally lower (90\%). From this study, we concluded that there was not much difference between microwave and normal thermal conditions except that the rate of disintegration of $\mathbf{1 a}$ to 2a under microwave conditions was faster by a factor of $1.5 \times 10^{2}$ compared to that of thermal conditions,

$$
\begin{aligned}
& 2 \mathrm{NaI}+\mathrm{CH}_{3} \mathrm{SOCH}_{3}+\mathrm{H}_{2} \mathrm{O} \rightarrow \\
& \qquad \mathrm{I}_{2}+\mathrm{CH}_{3} \mathrm{SCH}_{3}+2 \mathrm{NaOH} .
\end{aligned}
$$

From the results presented in table 1 it clear that both $\mathrm{NaX}(\mathrm{X}=\mathrm{Cl}, \mathrm{Br}, \mathrm{I})$ and $\mathrm{DMSO}$ are necessary for inducing the conversion of $\mathbf{1 a}$ to $\mathbf{2 a}$ via the RMA pathway. A possible mechanism for the transformation is given in figure 1 . We believe that under microwave/thermal conditions an electrophilic halide ion is generated, which helps to eject diethylmalonate $\mathbf{3}$ from the substrate in RMA fashion through intermediates 5 and $\mathbf{6}$. The electrophilic halide ion may be generated from the halogen molecule formed in situ, due to the oxidizing nature of DMSO, (1). Since open vessels were used for conducting the microwavemediated reaction, we believe that atmospheric or dissolved water plays a role in the generation of electrophilic iodide ion as given in (1). Previously, Watt and $\mathrm{Ji}^{13}$ reported the use of sodium iodide and chloramine $\mathrm{T}$ in DMSO for iodination of phenols. In this transformation, sodium iodide was the source for electrophilic iodine and chloramine $\mathrm{T}$ was used as an oxidizing agent. To best of our knowledge, ours is the first report of the formation of an electrophilic halide ion from NaX/DMSO.

Support for the proposed mechanism also came from the following observations. We noted that the reaction mixture for the conversion of $\mathbf{1 a}$ to $\mathbf{2 a}$ emitted the pungent smell of dimethyl suphide, even though we could not gather any experimental proof of its formation. We observed the conversion of $\mathbf{1 a}$ to $\mathbf{2 a}$ with $\mathrm{I}_{2} / \mathrm{DMSO}$ under microwave conditions (entry 14 , table 1), indicating that the electrophilic iodonium ion is indeed responsible for the transformation.

There was no reaction, when the monoester 4 was exposed to microwaves in the presence of sodium iodide in DMSO. The starting material 4 was recovered unchanged even after $10 \mathrm{~min}$ (scheme 2). This result is possibly due to the fact that diethyl malonate is a better leaving group compared to ethyl acetate. Similarly, the alcohol $\mathbf{7}$ did not undergo any change, showing that the keto group in $\mathbf{1 a}$ is necessary for ejecting the diethyl malonate unit.

To test the generality of the reaction, and to evaluate the electronic influence of substituents on the aromatic rings, the diesters $\mathbf{1 b}-\mathbf{c}$ were exposed to microwaves in the presence of NaI/DMSO (scheme 3 and table 2). In both the cases the RMA products $\mathbf{2 b - c}$ along with diethyl melonate $\mathbf{3}$ were obtained in near quantitative yields. The result shows that the electron-withdrawing $(\mathrm{Cl}, \mathbf{1 b}$, entry 2 , table 2$)$ or -donating $\left(\mathrm{CH}_{3}, \mathbf{1 c}\right.$, entry 3 , table 2$)$ nature of the substituents on the aromatic ring of $1 \mathbf{a}$ did not have much effect on the course of the reaction.

When dimethyl 2-(1-benzoyl-3-oxo-3-phenylpropyl) malonate 1d was subjected to microwave irradiation in the presence of NaI/DMSO the reac-

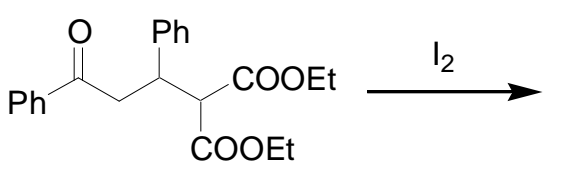

$1 \mathbf{a}$

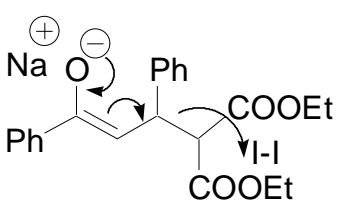

5

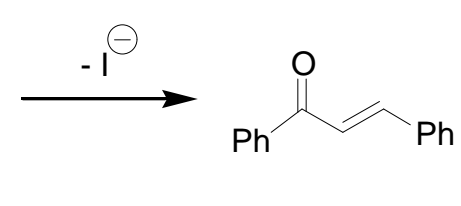

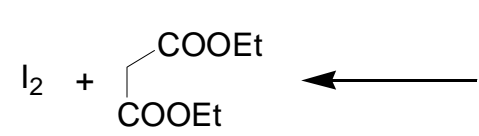

3
$2 a$

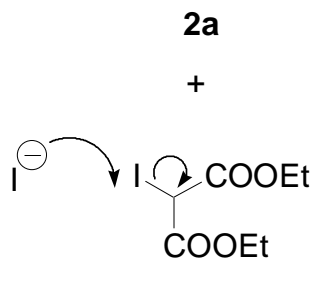

6

Figure 1. Mechanism for the conversion of 1,5-ketoester 1a to enone 2a and diethylmalonate $\mathbf{3}$. 


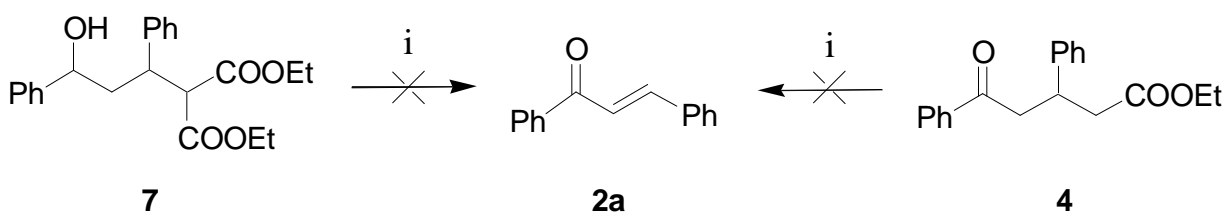

Scheme 2. Reagents and conditions: (i) NaI, DMSO, MW, 200-400 W, $10 \mathrm{~min}$.

Table 2. Reaction of Michael adducts $\mathbf{1 a}-\mathbf{h}$ with NaI in DMSO under microwave irradiation at $450 \mathrm{~W}$ at $2 \mathrm{~min}$.

\begin{tabular}{lllllcrc}
\hline Sl. no. & \multicolumn{1}{c}{$\mathrm{R}^{1}$} & \multicolumn{1}{c}{$\mathrm{R}^{2}$} & $\mathrm{X}$ & $\mathrm{Y}$ & $\begin{array}{c}\text { Michael } \\
\text { adduct }\end{array}$ & Product & Yield (\%) \\
\hline 1 & $\mathrm{C}_{6} \mathrm{H}_{5}$ & $\mathrm{C}_{6} \mathrm{H}_{5}$ & $\mathrm{COOEt}$ & COOEt & $\mathbf{1 a}$ & $\mathbf{2 a}^{[\mathrm{a}]}$ & 97 \\
2 & $4-\mathrm{ClC}_{6} \mathrm{H}_{4}$ & $\mathrm{C}_{6} \mathrm{H}_{5}$ & $\mathrm{COOEt}$ & COOEt & $\mathbf{1 b}$ & $\mathbf{2 b}{ }^{[\mathrm{a}]}$ & 98 \\
3 & $4-\mathrm{CH}_{3} \mathrm{C}_{6} \mathrm{H}_{4}$ & $\mathrm{C}_{6} \mathrm{H}_{5}$ & $\mathrm{COOEt}$ & $\mathrm{COOEt}$ & $\mathbf{1 c}$ & $\mathbf{2 c}^{[\mathrm{a}]}$ & 93 \\
4 & $\mathrm{C}_{6} \mathrm{H}_{5}$ & $\mathrm{COC}_{6} \mathrm{H}_{5}$ & $\mathrm{COOEt}$ & $\mathrm{COOEt}$ & $\mathbf{1 d}$ & $\mathbf{2 d}^{[\mathrm{a}]}$ & 85 \\
5 & $\mathrm{C}_{6} \mathrm{H}_{5}$ & $\mathrm{C}_{6} \mathrm{H}_{5}$ & $\mathrm{COOEt}$ & $\mathrm{COC} \mathrm{H}_{5}$ & $\mathbf{1 e}$ & $\mathbf{2 a}$ & 92 \\
6 & $\mathrm{C}_{6} \mathrm{H}_{5}$ & $\mathrm{C}_{6} \mathrm{H}_{5}$ & $\mathrm{COOEt}$ & $\mathrm{CN}$ & $\mathbf{1 f}$ & $\mathbf{2 a}$ & 93 \\
7 & $\mathrm{C}_{6} \mathrm{H}_{5}$ & $\mathrm{C}_{6} \mathrm{H}_{5}$ & $\mathrm{CO}\left(\mathrm{CH}_{2}\right)_{4}$ & - & $\mathbf{1 g}$ & $\mathbf{2 a}$ & 90 \\
8 & $\mathrm{C}_{6} \mathrm{H}_{5}$ & $\mathrm{C}_{6} \mathrm{H}_{5}$ & $\mathrm{CO}\left(\mathrm{CH}_{2}\right)_{5}$ & - & $\mathbf{1 h}$ & $\mathbf{2 a}$ & 89 \\
\hline
\end{tabular}

${ }^{[\mathrm{a}]}$ Reference 15<smiles>[R]C(=O)CC([R])C([X])[X]</smiles>

$1 b-h$

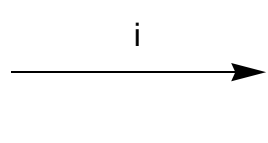

1b: $R^{1}=4-\mathrm{ClC}_{6} \mathrm{H}_{4}, \mathrm{R}^{2}=\mathrm{C}_{6} \mathrm{H}_{5}, \mathrm{X}=\mathrm{Y}=\mathrm{COOEt}$

1c: $\mathrm{R}^{1}=4-\mathrm{CH}_{3} \mathrm{C}_{6} \mathrm{H}_{4}, \mathrm{R}^{2}=\mathrm{C}_{6} \mathrm{H}_{5}, \mathrm{X}=\mathrm{Y}=\mathrm{COOEt}$

1d: $R^{1}=\mathrm{C}_{6} \mathrm{H}_{5}, \mathrm{R}^{2}=\mathrm{COC}_{6} \mathrm{H}_{5}, X=\mathrm{Y}=\mathrm{COOEt}$

1e: $R^{1}=R^{2}=C_{6} H_{5}, X=$ COOEt, $Y=C C O C_{6} H_{5}$

1f: $R^{1}=R^{2}=\mathrm{C}_{6} \mathrm{H}_{5}, X=$ COOEt, $Y=C N$

1g: $R^{1}=R^{2}=\mathrm{C}_{6} \mathrm{H}_{5}, X=\mathrm{CO}\left(\mathrm{CH}_{2}\right)_{4}, Y=H$

1h: $R^{1}=R^{2}=\mathrm{C}_{6} \mathrm{H}_{5}, X=\mathrm{CO}\left(\mathrm{CH}_{2}\right)_{5}, Y=H$<smiles>[R]C=CC([R])=O</smiles>

2a-d

2a: $R^{1}=R^{2}=\mathrm{C}_{6} \mathrm{H}_{5}$

2b: $\mathrm{R}^{1}=4-\mathrm{ClC}_{6} \mathrm{H}_{4}, \mathrm{R}^{2}=\mathrm{C}_{6} \mathrm{H}_{5}$ 2c: $R^{1}=4-\mathrm{CH}_{3} \mathrm{C}_{6} \mathrm{H}_{4}, \mathrm{R}^{2}=\mathrm{C}_{6} \mathrm{H}_{5}$ 2d: $R^{1}=\mathrm{C}_{6} \mathrm{H}_{5}, \mathrm{R}^{2}=\mathrm{COC}_{6} \mathrm{H}_{5}$

Scheme 3. Reagents and conditions: (i) NaI, DMSO, MW, $450 \mathrm{~W}, 2 \mathrm{~min}, 75-98 \%$.

tion resulted in $(E)$-1,4-diphenyl-2-butene-1,4-dione (dibenzoyl ethylene, 2d), along with diethyl melonate $\mathbf{3}$, formed without any event (entry 4 , table 2 ; scheme 3).

Next, we studied the microwave-mediated RMA reaction on the Michael adducts $\mathbf{1 e - h}$ as shown in table 2 (scheme 3). It can be seen from table 2 that excellent yields of RMA product 2a were obtained in all the cases. Surprisingly, even the adducts $\mathbf{1 g}$ and $\mathbf{1 h}$ underwent RMA reaction under microwave conditions to eject cyclopentanone and cyclohexa- none respectively, albeit in lower yields. The results show that apart from diethyl melonate, ethyl benzoylacetate (entry 5 , table 2 and $\mathbf{1 e} \rightarrow \mathbf{2 a}$ ), ethyl cyanoacetate (entry 6 , table 2 and $\mathbf{1 f} \rightarrow \mathbf{2 a}$ ), cyclohepentanone (entry 7 , table 2 and $\mathbf{1 g} \rightarrow \mathbf{2 a}$ ), and cyclohexanone (entry 8 , table 2 and $\mathbf{1 f} \rightarrow \mathbf{2 a}$ ) also are good leaving groups under the present conditions.

In conclusion, we have shown that facile RMA reaction on 1,5-ketodiesters/1,5-diketones takes place when adducts are exposed to microwaves in the presence of NaI/DMSO. Mechanistic studies have 
shown that $\mathrm{NaI} / \mathrm{DMSO}$ system is better than $\mathrm{NaCl} /$ DMSO and presence of DMSO is necessary to promote the RMA pathway.

\section{Experimental section}

All reagents and solvents were purchased from EMerck and Sisco Chemicals, India. Microwave reactions were carried out using Samsung, India; monomode and multi-power microwave oven (power source: $230 \mathrm{~V}, 50 \mathrm{~Hz}$, microwave frequency: $2450 \mathrm{MHz}$ ). The TLC (pre-coated silica gel $60 \mathrm{~F}_{254}$, Merck) method was used to monitor the progress of the reaction. Melting points were noted using a Gallenkamp melting point apparatus. IR spectra were recorded as $\mathrm{KBr}$ pellets using a Bomem MB104 spectrometer. The frequencies at which the ${ }^{1} \mathrm{H}$ NMR and ${ }^{13} \mathrm{C}$ NMR were recorded in $\mathrm{CDCl}_{3}$ on a Bruker $300 \mathrm{MHz}$ NMR instrument are noted in the spectral data. TMS was used as internal standard. GC analysis was performed on a Systronic (Model: 5700; detector: FID). All starting materials $\mathbf{1 a}-\mathbf{h}$ and products $2 \mathbf{a}-\mathbf{d}$ are known. ${ }^{14,15}$ The authenticity of the starting materials and the products were ensured on the basis of spectroscopic, and analytical data and by comparison with authentic samples.

\subsection{General procedure for microwave-mediated} RMA reaction: Diethyl 2-(3-oxo-1,3-diphenylpropyl)malonate 1a with NaI/DMSO

A $25-\mathrm{mL}$ conical flask, charged with Michael adduct 1 a $(500 \mathrm{mg}, 1.33 \mathrm{mmol})$ and sodium iodide $(408 \mathrm{mg}$, $2.71 \mathrm{mmol})$ in DMSO (2 mL) was irradiated in the microwave oven at $450 \mathrm{~W}$ for $2 \mathrm{~min}$. After completion of the reaction (TLC), it was cooled (rt), the reaction mixture was transferred into water $(10 \mathrm{~mL})$ and the aqueous layer was extracted with dichloromethane $(2 \times 10 \mathrm{~mL})$. GC analysis showed the formation of diethyl malonate and chalcone in equal proportions. Removal of solvent after drying with anhydrous $\mathrm{Na}_{2} \mathrm{SO}_{4}$ resulted in crude product, which was purified on a short column of silica $(1 \mathrm{~cm} \times$ $10 \mathrm{~cm}$ ) by eluting with increasing percentage of ethyl acetate in hexane $(1 \% \rightarrow 3 \%)$. Removal of solvent from pooled fractions resulted in the separation of (E)-1,3-diphenyl-2-propen-1-one $\mathbf{2 a}$ and diethyl malonate $\mathbf{3}$. Analytically pure sample of $\mathbf{2 a}(275 \mathrm{mg}$, $97 \%$ ) was obtained by recrystallization from DCM/ hexanes $(2: 98)$.
3.2 (E)-1-(4-chlorophenyl)-3-phenyl-2-propen-1one (2b) and diethyl malonate

Following the above general procedure, Michael adduct, diethyl 2-[3-(4-chlorophenyl)-3-oxo-1-phenylpropyl]malonate, $\mathbf{1 b}(100 \mathrm{mg}, 0.25 \mathrm{mmol})$, was transformed to $\mathbf{2 b}$ with sodium iodide $(75 \mathrm{mg}$, $0.5 \mathrm{mmol})$ in DMSO (1 mL) under microwave irradiation at $450 \mathrm{~W}$ for $2 \mathrm{~min}$. Yield of 2a: $60 \mathrm{mg}(98 \%)$.

\section{3 (E)-1-(4-methylphenyl)-3-phenyl-2-propen-1-} one (2c) and diethyl malonate

Following the above general procedure, Michael adduct, diethyl 2-[3-(4-methylphenyl)-3-oxo-1-phenylpropyl]malonate 1c $(100 \mathrm{mg}, 0 \cdot 26 \mathrm{mmol})$ was transformed to $2 \mathrm{c}$ with sodium iodide $(78 \mathrm{mg}, 0.52 \mathrm{mmol}$ ) in DMSO $(1 \mathrm{~mL})$ under microwave irradiation at $450 \mathrm{~W}$ for $2 \mathrm{~min}$. Yield of 2a: $54 \mathrm{mg}$ (93\%).

\section{4 (E)-1,4-diphenyl-2-butene-1,4-dione (diben- zoyl ethylene, 2d) and diethyl malonate}

Following the above general procedure, Michael adduct, diethyl 2-(1-benzoyl-3-oxo-3-phenylpropyl) malonate 1 d $(100 \mathrm{mg}, 0.22 \mathrm{mmol})$ was transformed to 2 d with sodium iodide $(67 \mathrm{mg}, 0.44 \mathrm{mmol})$ in DMSO $(1 \mathrm{~mL})$ under microwave irradiation at $450 \mathrm{~W}$ for $2 \mathrm{~min}$. Yield of 2a: $55 \mathrm{mg}(85 \%)$.

\section{5 (E)-1,3-diphenyl-2-propen-1-one (2a) and ethyl 3-oxo-3-phenylpropanoate}

Following the above general procedure, Michael adduct, ethyl 2-benzoyl-5-oxo-3,5-diphenylpentanoate 1e $(100 \mathrm{mg}, 0.26 \mathrm{mmol})$ on treatment with sodium iodide $(76 \mathrm{mg}, 0.5 \mathrm{mmol})$ in DMSO $(1 \mathrm{~mL})$ under microwave irradiation at $450 \mathrm{~W}$ for 2 min was transformed to 2a and ethyl 3-oxo-3-phenylpropanoate. Yield of 2a: $48 \mathrm{mg}$ (92\%); yield of ethyl 3-oxo-3phenylpropanoate: $42 \mathrm{mg}$ (88\%).

\section{6 (E)-1,3-diphenyl-2-propen-1-one (2a) and ethyl cyanoacetate}

Following the above general procedure, Michael adduct, Ethyl 2-cyano-5-oxo-3,5-diphenylpentanoate 1f $(100 \mathrm{mg}, 0.30 \mathrm{mmol})$ was transformed to $2 \mathrm{a}$ with sodium iodide $(100 \mathrm{mg}, 0.66 \mathrm{mmol})$ in DMSO $(1 \mathrm{~mL})$ 
under microwave irradiation at $450 \mathrm{~W}$ for $2 \mathrm{~min}$. Yield of 2a: $60 \mathrm{mg}$ (93\%); formation of ethyl cyanoacetate was detected by GC.

\section{7 (E)-1,3-diphenyl-2-propen-1-one (2a) and cyclopentanone}

Following the above general procedure, Michael adduct, 2-(3-oxo-3-phenylpropyl)-1-cyclopentanone $\mathbf{1 g}$ (100 $\mathrm{mg}, 0.33 \mathrm{mmol}$ ) was transformed to $\mathbf{2 a}$ with sodium iodide (100 mg, $0.67 \mathrm{mmol})$ in DMSO (1 mL) under microwave irradiation at $450 \mathrm{~W}$ for $2 \mathrm{~min}$. Yield of 2a: $64 \mathrm{mg}$ (90\%); yield of cyclopentanone: $25 \mathrm{mg}(86 \%)$.

\section{8 (E)-1,3-Diphenyl-2-propen-1-one (2a) and cyclohexanone}

Following the above general procedure, Michael adduct, 2-(3-oxo-3-phenylpropyl)-1-cyclohexanone $\mathbf{1 h}$ (100 $\mathrm{mg}, 0.33 \mathrm{mmol}$ ) was transformed to $\mathbf{2 a}$ with sodium iodide (100 mg, $0.67 \mathrm{mmol})$ in DMSO (1 mL) under microwave irradiation at $450 \mathrm{~W}$ for $2 \mathrm{~min}$. Yield of 2a: $61 \mathrm{mg}(89 \%)$; yield of cyclohexanone: $28 \mathrm{mg}(87 \%)$.

\subsection{General procedure for RMA reaction under} thermal condition: (E)-1,3-diphenyl-2-propen-1-one (2a) and diethyl malonate

A $10 \mathrm{~mL}$ round-bottom flask, charged with Michael adduct, diethyl 2-(3-oxo-1,3-diphenylpropyl)malonate $1 \mathbf{a}(100 \mathrm{mg}, 0.27 \mathrm{mmol})$ and sodium iodide (40.7 $\mathrm{mg}, 0.27 \mathrm{mmol})$ in DMSO $(2 \mathrm{~mL})$ was heated to $160^{\circ} \mathrm{C}$ for $5 \mathrm{~h}$. After completion of the reaction (TLC), it was cooled (rt), and the reaction mixture was transferred into water $(20 \mathrm{~mL})$. After due work up and chromatographic purification as described previously, the reaction furnished 2a. Analytically pure sample of $\mathbf{2 a}(54 \mathrm{mg}, 96 \%)$ was obtained by recrystallization from DCM/hexanes (2:98).

\section{Acknowledgments}

SJ thanks Council of Scientific and Industrial Research, New Delhi for a fellowship. HSPR thanks the UGC-SAP programme and the CSIR for financial support. We thank Prof A Srikrishna of the Indian Institute of Science for spectra and helpful discussions.

\section{References}

1. Koga K 1987 Organic synthesis: Modern trends (ed.) Chizhov (Oxford: Blackwell Scientific) p 285

2. Krapcho A P, Glynn G A and Grenon B J 1967 Tetrahedron Lett. 8215

3. Krapcho A P and Mundy B P 1970 Tetrahedron 26 5437

4. Van Tamelen E E and Anderson R J 1972 J. Am. Chem. Soc. 948225

5. Davis D D and Bigelow N B 1973 Tetrahedron Lett. 14 149

6. Reichardt C 1990 Solvents and solvent effects in organic chemistry 2nd edn (New York: Cambridge University Press)

7. Loupy A, Pigeon P, Ramdani M and Jacquault P 1993 J. Chem. Res. (S) 36

8. Shabat D, Rader C, List B, Lerner R A and Barbas C F III 1999 Proc. Natl. Acad. Sci. USA 966925

9. Langer P and Holtz E 2003 Synlett 402

10. Allen C F and Happ G P 1964 Can. J. Chem. 42655

11. Neto F R A, Trende J M and Albrecht P 1986 Tetrahedron 425621

12. Wang J X and Li T S 1999 Collect. Czech. Chem. Commun. 64107

13. Kometani T, Watt D S and Ji T 1985 Tetrahedron Lett. 262043

14. Dhar D N and Barton S D 1981 The chemistry of chalcone and related compounds (New York: John Wiley \& Sons)

15. (a) Ma A Y and Yongmin Zhang Y 2002 Synth. Commun. 32 819; (b) Garcia-Raso A, Garcia-Raso J, Campaner B, Mestres R and Sinisterra J V 1982 Synthesis 1037; (c) Nelson J H, Howells P N, DeLullo G C and Landen G L 1980 J. Org. Chem. 451246 